\title{
INFLUENCE OF KPI OF LOGISTICS PROCESSES ON LOGISTICS COSTS
}

\author{
Vukašin Pajić1 ${ }^{1}$ Gordana Radivojević ${ }^{2}$, Milorad Kilibarda ${ }^{3}$ \\ 1,2,3 University of Belgrade, Faculty of Transport and Traffic Engineering, Vojvode Stepe 305, 11000 \\ Belgrade, Serbia
}

Received 11 March 2021; accepted 2 May 2021

\begin{abstract}
Logistics processes due to their complexity in terms of a large number of activities and participants are cost generators. For this reason, many logistics companies plan and control the implementation of these processes in order to reduce costs. One of the tools used on this occasion is the key performance indicators (KPI) that are introduced, measured and monitored by logistics subsystems. The aim of this paper is to determine which KPIs are used in the ordering, warehouse and transport subsystems, as well as the impact of these KPIs on logistics costs. Based on a review of the literature and the most commonly used KPIs in logistics subsystems (ordering, warehouse, transport), hypotheses were developed and then tested using linear regression. In order to determine the impact of KPI of logistics processes on logistics costs, a survey was developed for logistics professionals in Serbia and sent to 50 addresses, of which 35 answers were valid.
\end{abstract}

Key words: key performance indicators, logistics costs, ordering, warehouse, transport.

\section{Introduction}

The focus of many logistics companies today is measuring, monitoring and minimizing business costs. As there are a large number of activities and participants in logistics, it is clear that the issue of minimizing business costs is very complex. In order to monitor their performance but also to achieve cost savings, companies define, measure and monitor KPI. In order to minimize costs, companies must identify the main cost drivers by processes and activities in order to adequately implement the necessary measures to reduce and/or eliminate them. In doing so, quality tools as well as a quality management system can be of great help. The quality tools that can be especially important when determining the cost drivers by activities, the process flow diagram (process mapping) stands out. Also, based on a review of the literature, it was established that lean methodology tools are used, such as Six Sigma methodology $(6 \sigma)$ and $5 S$ (Sort, Set in Order, Shine, Standardize, Sustain). Quality management, in addition to reducing costs, also increases the competitiveness of the company, given that efficient quality management also affects the quality of service provided, which creates satisfied customers. Certainly, good quality also brings with it certain costs (such as the costs of introducing standards, maintaining standards, certification, etc.), but in this paper, the emphasis is placed on the analysis of poor quality and its impact on the costs of logistics companies.

${ }^{1}$ Corresponding author: v.pajic@sf.bg.ac.rs 
The aim of this paper is to determine the impact of KPIs and the quality of logistics processes on the costs of a logistics company. Three logistic subsystems were observed in the paper: ordering, warehousing and transport. Based on the analysis of logistics companies, it is estimated that these subsystems are the largest cost drivers. Namely, all errors that occur in the ordering subsystem during the receipt and processing of the order affect not only the costs of this subsystem but if the error is not detected in time, they can also affect the costs in other subsystems. An error in order processing can cause costs in the picking process. Errors in the picking process then affect the generation of additional transport costs (since it is necessary to return incorrectly delivered products). Based on this, it can be concluded how much the error in these subsystems can have on the costs and profitability of the company.

The paper is organized as follows. The second chapter presents a review of the literature and hypotheses development. A description of the methodology and the analyzed sample are presented in the third chapter. The fourth chapter describes the results of hypotheses testing and discussions of the obtained results. At the very end of the paper, concluding remarks and directions of future research are given.

\section{Literature Review and Hypotheses Development}

The main cost drivers in logistics are the subsystems of ordering, warehousing and transport. For each of the mentioned subsystems, based on the literature review, the KPIs used in them were defined as well as hypotheses that will be tested.

\subsection{Ordering}

One of the basic subsystems of logistics whose activities trigger a number of other activities required to deliver a particular product to end-users is ordering. In this subsystem, activities such as receiving an order, processing an order and executing an order take place (by sending picking orders). In order for companies to determine the efficiency of this subsystem, it is necessary to define and monitor KPIs. The ordering process KPIs can be divided into the following groups:

- KPIs related to users;

- KPIs related to internal logistics;

- KPIs related to workers (administration and order pickers); and

- Financial KPIs.

Nowadays, users expect the processing time of the order to be as short as possible. In addition to processing speed, another quality $\mathrm{KPI}$ of this process is the accuracy of order processing. It is these two quality KPIs that represent the competitiveness factors of a logistics company.

KPIs related to users that are most frequently monitored are:

- On-time shipping;

- Total order cycle time;

- Internal order cycle time; and

- Perfect order percentage.

On-time shipping can be expressed as a percentage of deliveries made in the agreed time and can be calculated as the quotient of the number of deliveries on time and the total number of deliveries. The importance of on-time delivery for the user is shown by the fact that the probability of repurchase is lower if the order is not realized within two 
days in relation to the agreed delivery date, with $69 \%$ of users (Conveyco, 2016). The total order cycle time is an important KPI for the company, considering that by reducing this time, the company simultaneously increases customer satisfaction and also increases profit. This KPI can be calculated as the quotient of the difference between the moment of receipt of the order and the moment of processing and the total number of shipped orders. Internal order cycle time depends a lot on the efficiency of the processes that take place in the warehouse, especially on the efficiency of the picking process. For that reason, it is necessary to have trained workers as well as adequate technology. This KPI can be calculated as the quotient of the difference between the time of order shipment and the moment of order receipt and the total number of shipped orders. A perfect order is considered to be an order that is delivered on time, complete, without damage and with correct documents. Research shows that with an increase in successfully realized orders of $3 \%$ there is an increase in the profit margin of $1 \%$ (Conveyco, 2016). Perfect order percentage can be calculated as the product of the percentage of deliveries on time, complete deliveries, deliveries without damage and deliveries with complete documentation (Conveyco, 2016).

KPIs related to internal logistics that are most frequently monitored are:

- Dock-to-Stock cycle time;

- Inbound orders received; and

- Lines received and put away.

Dock-to-Stock cycle time is crucial for efficient business, and it is necessary to strive to reduce the time required for receiving and storing pallets so that the company does not end up in a situation where there are no goods in stock and can not meet customer requirements. Research shows that $7-25 \%$ of users will continue to buy but will not buy a replacement product, while $21-43 \%$ of users will look for a product with competitors when faced with a lack of product inventory (Conveyco, 2016). Dock-to-Stock cycle time can be calculated as the quotient of the sum of reception times for all suppliers (expressed in hours) and the total number of pallet receipts from suppliers. Inbound orders received can be expressed as the number of processed picking orders per person within one hour from the moment of receiving the order. This number can be calculated as the quotient of the total number of processed orders and the total working time of workers (expressed in hours). The number of lines received and put away can be expressed as the number of processed items per person within one hour from the moment of receipt of the order. The efficiency and value of this KPI are greatly influenced by the applied picking technology. This KPI can be calculated as a quotient of the total number of items and the total working time of workers (expressed in hours).

KPIs related to workers that are most frequently monitored are:

- Fill rate - orders;

- Fill rate - line items;

- Orders picked per hour; and

- Lines picked and shipped per hour.

The fill rate for orders can be calculated as a quotient of the total number of filled orders according to customer requirements and the total number of filled orders. On the other hand, the fill rate for line items can be calculated as the quotient of the total number of completely filled order lines and the total number of order lines filled. The number of orders picked per hour is a measure of 
the efficiency of the picking and shipping process. This number can be calculated as the quotient of the total number of picked and shipped orders and the total time spent on picking and shipping processes (expressed in hours). Similar to this is the last KPI from this group, which refers to the number of picked and shipped items per hour. This KPI can be calculated as the quotient of the total number of successfully picked and shipped items and the total time required for picking and shipping processes (expressed in hours).

Financial KPIs that are most frequently monitored are:

- Distribution cost as a percentage of sales;

- Distribution cost per unit shipped; and

- Inventory days of supply.

Distribution cost as a percentage of sales can be calculated as the ratio of total distribution costs and total sales, while distribution cost per shipped unit can be calculated as the ratio of total distribution costs and a total number of shipped product units.

Based on research (Mensak, 2019), it was found that ordering errors have an impact on sales, profitability, efficiency and productivity of the company. On average, ordering errors led to a $6-10 \%$ reduction in the company's profitability, efficiency and productivity and a $1-5 \%$ reduction in sales. Another research (Driscoll, 2016) shows that there is a big difference in terms of order processing costs between companies that are at the very top according to this KPI and those that are very bad according to this KPI. The processing cost for top companies is 5.11 per order while the same cost for companies that are very bad is as high as $40.87 \$$ per order. Based on this data, it can be concluded that effective management of this process can achieve significant savings. The costs of order processing also depend on the method of processing, where two basic methods are distinguished, namely traditional (paper processing) and modern (email, cloud solutions, etc.). When observing the average cost of order processing by channels, a difference between companies that are at the very top and at the very bottom can be seen. Namely, the cost of companies that are at the very top for the traditional way of processing is $7 \$$, while for worse companies it is as much as $21 \$$. When observing the modern way of processing, it can be concluded that in this case also there is a difference, given that the cost of processing for top companies is $2 \$$ while for worse companies it is $6 \$$ (Driscoll, 2016). In addition to reducing costs, the modern way of processing orders also enables faster processing, greater data accuracy, greater control, higher productivity, etc. The issue of reducing the cost of ordering has been recognized in the literature. Thus, the authors (Uthayakumar and Rameswari, 2012) in their paper have developed an inventory management model that seeks to reduce order processing costs. A similar issue was addressed by the authors (Woo et al., 2000) in their paper where they presented a model for reducing the cost of order processing using information technology.

Increasing the flexibility of ordering directly affects the increase in costs since it is necessary to implement a larger number of activities in order to meet customer requirements. However, increasing flexibility in some cases does not necessarily lead to increased costs, as the results of the study show (Ishfaq and Narayanan, 2018). Namely, in their paper, the authors analyzed how order-trades and distribution-trades affect costs in the car supply chain. The results of 
the research showed that the application of these sales strategies leads to an increase in flexibility without increasing costs for the manufacturer. When observing the entire supply chain, it can be concluded that these strategies lead to a reduction in inventory, a reduction in lost sales and a reduction in logistics costs. However, as the automotive supply chain is very specific (in terms of the goods themselves, but also the time required for the production and delivery of products), this paper analyzes whether increasing the flexibility of ordering affects the generation of additional costs. In their paper (Susanto et al., 2016), authors dealt with the improvement of the ordering process in the company, since retention during the processing of orders negatively affected the company's business. In order to determine the most significant causes of delays, they applied the DMAIC (Define, Measure, Analyze, Improve and Control) cycle as one of the tools of the $6 \sigma$ methodology. After the analysis, they came to the conclusion that the discrepancy in the level of stocks, as well as the limited capabilities of distributors, are the most important factors that cause delays in order processing. That efficient management of the ordering process can contribute to cost reduction not only in the ordering process but also to the entire supply chain is also shown by the paper $(\mathrm{Li}$ and Choi, 2017). In this paper, the authors examined the influence of order realization time on the bullwhip effect. The results of the research showed that reducing the time of order realization can affect four significant causes of the bullwhip effect (demand forecast, price fluctuation, forecasting product shortages and merging orders) at the same time.

Based on all the above, the following hypotheses were developed:

H1a: Ordering flexibility influence an increase in costs.

H1b: Order processing time influence an increase in costs.

H1c: Ordering errors influence an increase in costs. H1d: Quality management in the ordering process reduces costs.

\subsection{Warehousing}

Within the warehousing subsystem, activities related to the processes of receiving goods, disposal, storage, order picking and shipping are realized. Receipt of goods includes activities of assigning a loading ramp to each truck, as well as activities related to unloading vehicles. Disposal of goods involves the activities of handling pallets and determining the storage location. Storage involves moving the pallets from the receiving area to a specific storage location. Picking involves all activities necessary to prepare the goods in accordance with the requirements of users. This process is also the most demanding process of this subsystem that requires time and labor. Finally, the shipping process includes activities such as positioning the vehicle on the shipping ramp, packing the goods after the picking process and loading the vehicle. The KPIs that are the most frequently monitored within this subsystem are shown in Table 1. 
Table 1

KPIs by Warehousing Subsystem Activities

\begin{tabular}{|c|c|c|c|c|c|}
\hline & $\begin{array}{c}\text { Financial } \\
\text { KPIs }\end{array}$ & $\begin{array}{l}\text { Productivity } \\
\text { KPIs }(/ \mathbf{h})\end{array}$ & $\begin{array}{c}\text { Utilization } \\
\text { KPIs (\%) }\end{array}$ & $\begin{array}{l}\text { Quality } \\
\text { KPIs (\%) }\end{array}$ & $\begin{array}{l}\text { Cycle Time } \\
\text { KPIs (h) }\end{array}$ \\
\hline $\begin{array}{l}\text { Receiving } \\
\text { of Goods }\end{array}$ & $\begin{array}{l}\text { Receiving } \\
\text { cost }^{1}\end{array}$ & $\begin{array}{l}\text { Number of } \\
\text { receipts }\end{array}$ & $\begin{array}{l}\text { Dock door } \\
\text { utilization }\end{array}$ & $\begin{array}{l}\text { Receipts } \\
\text { processed } \\
\text { accurately }\end{array}$ & Receipt processing time \\
\hline Disposal & Disposal cost $\mathrm{t}^{2}$ & $\begin{array}{c}\text { Number of } \\
\text { disposed pallets }\end{array}$ & $\begin{array}{l}\text { Utilization of labor } \\
\text { and equipment }\end{array}$ & Perfect disposal & $\begin{array}{l}\text { Disposal cycle time } \\
\text { (per disposal) }\end{array}$ \\
\hline Storage & $\begin{array}{l}\text { Storage space } \\
\operatorname{cost}^{3}\end{array}$ & Inventory $\left(/ \mathrm{m}^{2}\right)$ & $\begin{array}{l}\text { Location and cube } \\
\text { occupied }\end{array}$ & $\begin{array}{c}\text { Locations } \\
\text { without inventory } \\
\text { discrepancies }\end{array}$ & Inventory days on hand \\
\hline $\begin{array}{c}\text { Order } \\
\text { Picking }\end{array}$ & Picking cost ${ }^{4}$ & Order lines picked & $\begin{array}{c}\text { Utilization of } \\
\text { picking labor and } \\
\text { equipment }\end{array}$ & $\begin{array}{l}\text { Perfect picking } \\
\text { lines }\end{array}$ & $\begin{array}{l}\text { Order picking cycle } \\
\text { time (per order) }\end{array}$ \\
\hline $\begin{array}{l}\text { Shipping } \\
\text { of Goods }\end{array}$ & $\begin{array}{c}\text { Shipping } \\
\text { cost }^{5}\end{array}$ & $\begin{array}{c}\text { Orders prepared } \\
\text { for shipment }\end{array}$ & $\begin{array}{c}\text { Utilization of } \\
\text { shipping docks }\end{array}$ & Perfect shipments & $\begin{array}{c}\text { Warehouse order cycle } \\
\text { time }\end{array}$ \\
\hline \multicolumn{6}{|c|}{$\begin{array}{l}{ }^{1} \text { - cost of receipt per item; } \\
{ }^{2} \text { - cost of disposal per item; } \\
{ }^{3} \text { - the cost of storage space per item; } \\
{ }^{4} \text { - picking cost per item; } \\
{ }^{5} \text { - shipping cost per order. }\end{array}$} \\
\hline
\end{tabular}

Source: (Frazelle, 2002)

Based on the research (Kusrini et al., 2018), the most significant KPIs were: productivity related to the process of receiving goods (number of receipts/h), duration of disposal (h), utilization of locations (\%) and spatial occupancy for the disposal process, picking duration for the picking process and productivity (number of prepared shipping orders/h) for the shipping process. When only the costs of storage and handling of goods are observed, then it can be concluded that the largest source of costs is related to workers (order pickers), as much as $60 \%, 25 \%$ goes to the cost of space and the remaining $15 \%$ to the cost of equipment. These data, once again confirm the fact that the picking process is one of the main cost drivers in the warehousing subsystem. For this reason, it is necessary to pay attention when defining the warehouse layout as well as when choosing the picking technology. The location of the picking zone can have an impact on storage costs. The authors (Apsalons and Gromov, 2017) dealt with this issue in their paper, where, based on research, they showed that locating the picking zone has an impact on costs. As for the costs of picking technology, it is necessary to find the optimum between the higher costs of implementing advanced technologies and the potential savings that can be achieved by applying such technologies. In order to reduce errors in the picking process, DHL has developed picking glasses using Augmented Reality (AR) technology. By using AR glasses, it is possible to achieve a productivity increase of about 15\% (DHL, 2015; DHL, 2019). In addition to improving productivity, the use of AR glasses also increases the accuracy of picking as well as reducing picking time and eliminating errors.

As already mentioned, the main cost driver in the warehousing subsystem is the picking process. During the picking process, $50 \%$ of the time goes to the movement of picking workers (Dukic and Oluic, 2007). For this 
reason, it is important to manage this process efficiently to reduce the distance traveled as well as costs. Cost reduction can be achieved by choosing the right picking technology. The authors (Dukic and Oluic, 2007) in their paper considered the impact of different picking technologies on the efficiency of the picking process. The results of the research showed that it is possible to achieve savings of $80 \%$ in terms of the distance traveled by the pickers by choosing an adequate picking technology. One of the better picking technologies was order batching technology, i.e. picking items that are close in location and are on different picking orders. The paper (Zimon, 2015) examined the impact of the quality management system on the improvement of the warehousing process. It is important to note that the analyzed quality management system is prescribed by the ISO 9001 standard. Based on the results of the conducted research, it was concluded that the implementation of the quality management system has a significant impact on the improvement of the warehousing process. This impact is reflected in the reduction of the number of complaints, the number of damage to items during storage and transport, the reduction of errors during shipment of goods, etc. (Zimon, 2015).

Having in mind the above, the following hypotheses were developed:

H2a: Picking control influence on reducing costs. $H 2 b$ : Introducing new picking technologies reduces costs.

H2c: Picking errors influence an increase in costs. H2d: Quality management in the warehousing process reduces costs.

\subsection{Transport}

In addition to warehousing, the transport subsystem is one of the generators of significant logistics costs. For this reason, it is necessary to define and monitor adequate KPIs in order to minimize these costs. A review of the literature found that different authors defined different KPIs for the transport process. Thus (Gozacan and Lafci, 2020) reviewed the literature and established the following KPIs that are used to monitor the transport process:

- Damage in transport;

- Reliability of delivery;

- Security of delivery;

- Urgent deliveries;

- Number of deliveries per vehicle/km;

- Number of deliveries on time;

- Effectiveness of the distribution process;

- Shipping errors; and

- Shipping/transport costs.

Of these KPIs, the number of on-time deliveries (52\% of papers) and shipping errors ( $28 \%$ of papers) were most frequently mentioned and used for the transport process in the literature (Gozacan and Lafci, 2020). As the transport subsystem is one of the main drivers of logistics costs, it is necessary to monitor, measure and control costs. In addition to the total costs, it is possible to distinguish between marginal and average costs in transport. Marginal costs include the costs incurred in transporting an additional unit of product. On the other hand, average costs are the costs that are obtained when the total costs are divided by the total number of transported units. When it comes to transportation costs then it is also possible to distinguish between internal and external transportation costs. Internal costs are related to the costs of product delivery, insurance, driver's salary, fleet maintenance, fuel, etc. On the other hand, external transport costs include the costs of air pollution, climate change, noise, accidents and traffic congestion (Mostert and Limbourg, 2016). 
Route selection, as well as routing strategies, can be crucial in terms of cost reduction. This claim is proven by a large number of papers in the literature that deals with routing analysis and the impact on costs. Ponboon et al. (2015) in their paper examined the impact of locating and routing on costs. The research analyzed several scenarios of locating objects and routing vehicles (as well as vehicle selection). The results of the research showed that depending on the routing strategy, it is possible to achieve cost savings. The problem of vehicle routing due to variable demand was also addressed by Mungwattana et al. (2019). Based on the results, it was concluded that the costs vary depending on the chosen vehicle routing strategy. Similar results were obtained by Jakara et al. (2019) who developed and applied a mathematical model for vehicle routing. The goal of applying this model was to minimize transportation costs. Damages in transport, as well as the return of incorrectly delivered products, entail an increase in costs since it is necessary to make a double delivery (thus doubling the costs). In addition to the delivery itself, the replacement of a damaged product generates additional costs (Germann, 2017). Given that the transport subsystem, as well as storage, can have a significant impact on costs, it is necessary to manage the quality of all activities that occur in the transport process. In the paper (Kryvoruchko et al., 2018), the authors examined the concepts, systemic approaches and models of transport service quality management, all with the aim of improving quality and thus reducing costs. By efficient management of logistics processes, it is possible to achieve savings in the total costs of the company in the amount of $15-20 \%$, with a reduction in logistics costs in the amount of $1 \%$ (Kryvoruchko et al., 2018). According to the authors (Šimkova et al., 2015), the quality of transport is influenced by transport infrastructure, transport technology, transport processes, information systems and human resources. Based on the research results, the authors came to the conclusion that there is a time difference between the implementation and the effect of introducing a quality management system, which is shorter in smaller companies. However, it has also been shown that the implementation of a quality management system has a positive impact on the transport KPIs, and most of all on the efficiency KPIs. The data of the author's research (Musau et al., 2017) show that efficient management of transport processes leads to the improvement of the company and the entire supply chain. Namely, the authors examined the effects of transport management on the company's performance in textile companies. The results of the research showed that the companies that introduced a defined time of vehicle reception, route planning, fleet management and vehicle tracking achieved performance improvement.

According to the literature, the following hypotheses have been developed:

$H 3 a$ : Vehicle routing strategy influences a reduction in costs.

H3b: Control of loaded goods influences a reduction in costs.

H3c: Returning incorrectly delivered products influence an increase in costs.

H3d: Damage during transport influences an increase in costs.

H3e: Quality management in the transport process reduces costs.

\section{Methodology}

Based on a systematic review of the literature, an instrument for measuring the impact of 
the performance of logistics subsystems (ordering, warehousing and transport) on the costs of a logistics company has been defined. The three basic groups of KPIs, as well as the influence related to their impact on logistics costs, are shown in Table 2.

Table 2

Variable Description

\begin{tabular}{|c|c|c|}
\hline $\begin{array}{l}\text { KPI of } \\
\text { logistics } \\
\text { processes }\end{array}$ & Influence of KPI on logistics costs & Reference \\
\hline $\begin{array}{l}\text { Ordering } \\
\text { KPI }\end{array}$ & $\begin{array}{l}\text { Ordering flexibility generates additional costs; } \\
\text { Order processing time increases costs; } \\
\text { Ordering errors generate additional costs; } \\
\text { Quality management of the ordering process reduces costs; }\end{array}$ & $\begin{array}{l}\text { Mensak, 2019; Susanto } \\
\text { et al., 2016; Li and Choi, } \\
2017 .\end{array}$ \\
\hline $\begin{array}{l}\text { Warehousing } \\
\text { KPI }\end{array}$ & $\begin{array}{l}\text { Picking control reduces costs; } \\
\text { The introduction of new picking technologies reduces the cost of errors; } \\
\text { Picking errors increase costs; } \\
\text { Quality management of the warehousing process reduces costs; }\end{array}$ & $\begin{array}{l}\text { Dukic and Oluic, 2007; } \\
\text { Zimon, } 2015 .\end{array}$ \\
\hline $\begin{array}{c}\text { Transport } \\
\text { KPI }\end{array}$ & $\begin{array}{l}\text { Vehicle routing strategy reduces costs; } \\
\text { Control of the loaded goods has the effect on reducing costs; } \\
\text { Transport damage increases costs; } \\
\text { Returning incorrectly delivered products generates additional costs; } \\
\text { Quality management of the transport process reduces costs. }\end{array}$ & $\begin{array}{l}\text { Šimkova et al., 2015; } \\
\text { Musau et al., 2017; } \\
\text { Kryvoruchko et al., } 2018 .\end{array}$ \\
\hline
\end{tabular}

Based on the developed instrument, an appropriate survey questionnaire was created. The questionnaire was used as a data collection tool. The questionnaire is composed of two parts, where the first part of the questionnaire contains questions in order to determine the characteristics of respondents and companies in which they work, while the second part contains questions to determine the impact of logistics subsystem KPIs on logistics company costs. In order to process the results, the Likert scale (1-5) was used. As mentioned earlier, the questionnaire was intended for logisticians in Serbia. An electronic version of the questionnaire was sent to 50 addresses but returned filled from 40 addresses. After selective analysis, responses that were not completely filled were excluded from further analysis which ended with 35 fully filled questionnaires.
The survey was conducted in the period from November to December 2020.

A sample of 35 responses was then statistically processed. Based on these results and Table 3 , it can be concluded that respondents work in companies of different sizes, in different positions and in different sectors. Namely, the results of Table 3 show that the largest percentage of respondents work in companies engaged in the distribution and domestic transport (60\%), followed by companies engaged in retail (20\%), international logistics and freight forwarding (14.3\%) and contract logistics - 3PL (5.7\%). In terms of company size, the largest percentage of respondents work in large companies (54.3\%) and medium-sized companies (37.1\%). The smallest number of respondents works in small companies (8.6\%). When looking at 
the results of employee position, then it can be concluded that the largest number of respondents is employed in the position of warehouse manager (40\%), followed by positions of logistics assistant (25.7\%), the dispatcher (20\%), while the smallest percentage of respondents work in development and planning (14.3\%).

Table 3

Descriptive Statistics

\begin{tabular}{|l|l|}
\hline Sample & Share (\%) \\
\hline Primary Business Activity & 14.3 \\
\hline International logistics and freight forwarding & 20.0 \\
\hline Retail & 5.7 \\
\hline Contract logistics - 3PL & 60.0 \\
\hline Distribution and domestic transport & \multicolumn{2}{|l|}{} \\
\hline Company Size & 8.6 \\
\hline Small company (up to 50 employees) & 37.1 \\
\hline Medium company (50-300 employees) & 54.3 \\
\hline Large company (over 300 employees) & \multicolumn{2}{|l|}{} \\
\hline Employee Position & 25.7 \\
\hline Logistics assistant & 40.0 \\
\hline Warehouse manager & 14.3 \\
\hline Development and planning & 20.0 \\
\hline Dispatcher &
\end{tabular}

IBM SPSS 25 was used to confirm the reliability of the analyzed sample. Reliability testing showed that the value of Cronbach's $a$ is 0.878 , which indicates an acceptable level of internal consistency (Hair et al., 2006). Since the reliability of the sample was confirmed, the hypotheses were tested (Figure 1). The results of the testing are presented below.

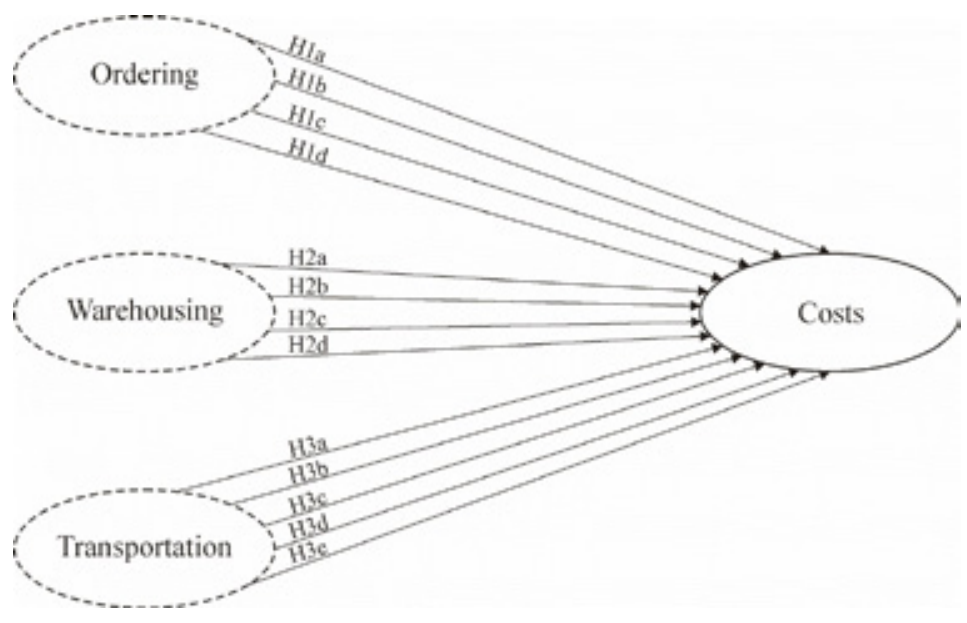

Fig. 1.

Conceptual Model of Logistics Performance and Costs 


\section{Results}

Based on the developed hypotheses in Chapter 2 , a more detailed analysis of their testing was performed in this chapter. Testing was performed using linear regression (Swanson, 2016; Helmy et al., 2018; Andrejić et al., 2020). Linear regression was used to predict the value of logistics costs as a dependent variable relative to the KPIs of logistics processes, as independent variables. In order to support a certain hypothesis, it is necessary to determine the values of the $\beta$ coefficient and the value of significance (Sig.). The value of the $\beta$ coefficient shows the relative importance of the independent variable. On the other hand, the value of Sig. shows the statistical significance of the independent variable in the model (where this value should be less than 0.1 ). The results of the linear regression are shown in Table 4. In this paper, one dependent and three independent variables were used. Costs were observed as the dependent variable while ordering KPIs, warehousing KPIs, and transport KPIs were observed as independent variables.

\section{Table 4}

Linear Regression Results

\begin{tabular}{|l|c|c|}
\hline \multirow{2}{*}{ Influence of KPI on Logistics Costs } & \multicolumn{2}{|c|}{ Costs } \\
\cline { 2 - 3 } & $\beta$ & Sig. \\
\hline Ordering flexibility influence an increase in costs (H1a) & 0.364 & 0.032 \\
\hline Order processing time influence an increase in costs (H1b) & 0.534 & 0.001 \\
\hline Ordering errors influence an increase in costs (H1c) & 0.484 & 0.003 \\
\hline Quality management in the ordering process reduces costs (H1d) & 0.705 & 0.000 \\
\hline Picking control influence on reducing costs (H2a) & 0.541 & 0.001 \\
\hline Introducing new picking technologies reduces costs (H2b) & 0.384 & 0.023 \\
\hline Picking errors influence an increase in costs (H2c) & 0.444 & 0.008 \\
\hline Quality management in the warehousing process reduces costs (H2d) & 0.727 & 0.000 \\
\hline Vehicle routing strategy influences a reduction in costs (H3a) & 0.385 & 0.023 \\
\hline Control of loaded goods influences a reduction in costs (H3b) & 0.564 & 0.000 \\
\hline Returning incorrectly delivered products influence an increase in costs (H3c) & 0.541 & 0.001 \\
\hline Damage during transport influences an increase in costs (H3d) & 0.438 & 0.008 \\
\hline Quality management in the transport process reduces costs (H3e) & 0.663 & 0.000 \\
\hline
\end{tabular}

Based on the results (Table 4) and the value of $\beta=0.364, p<0.05$, it can be concluded that the flexibility of ordering has an influence on the generation of additional costs. The flexibility of ordering can cause longer order processing times which directly affects the generation of additional costs. Based on this, it can be said that hypothesis $\mathrm{H} 1 \mathrm{a}$ has been supported. The results of the survey showed that about $63 \%$ of respondents when observing primary business activity agree with this hypothesis. Of that percentage, as many as $40 \%$ of them work in companies dealing with distribution and domestic transport. When looking at the results from the aspect of the company size, then it can be concluded that most respondents who work in medium and large companies (54\%) agreed with this hypothesis. The largest number of respondents who agreed with this hypothesis are logistics assistants and warehouse managers (about 43\%). The results of testing the next hypothesis $(\beta=0.534, p<0.05)$ confirm that the order processing time has 
an influence on the generation of additional costs, which supports hypothesis $\mathrm{H} 1 \mathrm{~b}$. The results of the survey showed that about $91 \%$ of respondents agreed with this hypothesis when observing the primary business activity of the company in which the respondents work (of which the largest percentage is employed in companies engaged in retail and distribution and domestic transport). Based on these results, it can be concluded that companies should work on improving and speeding up the order processing process in order to reduce costs. One way to speed up this process is to apply information technology (IT) for receiving and processing orders. The application of IT would directly affect the reduction of costs since the testing of hypothesis $\mathrm{H} 1 \mathrm{c}$ confirmed that errors in ordering have an influence on the generation of additional costs $(\beta=0.484, p<0.05)$. In this way, it would directly affect the reduction of order processing costs and the reduction of error costs. The results of the survey showed that employees in medium and large companies (83\%) agree with this hypothesis when observing company size. By efficiently managing the quality of the ordering process, it is possible to influence the reduction of ordering costs, which is supported by the values from Table 4 ( $\beta=$ $0.705, p<0.001$ ), which supports hypothesis H1d. Namely, with efficient management, it is possible to achieve savings not only in costs but also in time, since the need for double work is eliminated due to the elimination of errors. As many as $89 \%$ of respondents agreed with this hypothesis, of which the largest number of them are employed in the position of warehouse managers and development and planning.

The results of Table 4 and the values of $\beta$ $=0.541, p<0.05$ confirm that the picking control has an influence on cost reduction, which supported hypothesis H2a. Namely, by controlling the goods after the picking process and before the preparation for shipment, all errors that occurred during the picking process can be noticed and eliminated. In this way, the costs of external errors (when the user determines an error in the quantity or quality of the product) are reduced and/or eliminated, which are much higher than the costs of internal errors (when the error is determined in the warehouse). The results of the survey showed that the employees in international logistics and freight forwarding and distribution and domestic transport agreed the most with this hypothesis. Based on the values of $\beta=$ $0.384, p<0.05$, it was confirmed that the introduction of new picking technologies affects the reduction of errors and thus the reduction of costs, which supports hypothesis $\mathrm{H} 2 \mathrm{~b}$. Observed from the aspect of company size, the largest number of respondents who agreed with this hypothesis (29\%) work in large companies. In addition to reducing costs, the introduction of new picking technologies also increases the productivity of pickers. Reducing errors in the picking process also reduces the need for re-picking as a result of errors. An error in the picking process not only increases the costs incurred in the warehouse but also in the transport. Namely, if the error is not detected before the shipment of goods but after delivery, then there are additional costs for returning incorrectly prepared goods. Based on all the above, it can be concluded how important a mistake can be in the picking process and for that reason, it is necessary to effectively manage this process in order to reduce and/or eliminate errors. Based on the value of $\beta=0.444, p<0.05$, it can be concluded that hypothesis $\mathrm{H} 2 \mathrm{c}$ was also supported. When observing the positions of the respondents, the largest number of 
respondents working in the positions of warehouse managers and development and planning agreed with this hypothesis. Efficient management of the quality of the warehousing process can achieve significant savings, which is supported by the values of $\beta=0.727, p<0.001$, which supports hypothesis $\mathrm{H} 2 \mathrm{~d}$. Namely, the application of RFID tags for the identification of goods in warehousing processes could save time and costs. The majority of respondents working in companies dealing with international logistics and freight forwarding, retail and distribution and domestic transport (57\%) agreed with this hypothesis.

The vehicle routing strategy during delivery has a positive effect on cost reduction. Namely, by choosing the right route, as well as vehicles, it is possible to achieve savings in transport. Based on the test results $(\beta=$ $0.385, p<0.05$ ), it can be concluded that hypothesis $\mathrm{H} 3 \mathrm{a}$ was supported. The largest percentage of respondents $(60 \%)$ employed in the positions of warehouse managers and dispatchers agreed with this hypothesis. The values from Table $4(\beta=0.564, p<0.001)$ show that the control of loaded goods has an influence on cost reduction, which supports hypothesis $\mathrm{H} 3 \mathrm{~b}$. As already mentioned, the control of goods before shipment can detect and eliminate the error that occurred during the process of picking or preparation of goods for loading, which directly affects the reduction of costs. By crossing the size of the company in which the respondents work and the $\mathrm{H} 3 \mathrm{~b}$ hypothesis, it was concluded that the largest percentage of employees in large companies agreed with this hypothesis. Damage that occurs during the transport process has an influence on the increase in costs, as evidenced by the values of $\beta=$ $0.541, p<0.05$. When goods are damaged in transport, in addition to the costs of the damage itself, there are also costs caused by non-delivery of products, as well as costs of re-delivery of damaged products. Thus, hypothesis $\mathrm{H} 3 \mathrm{c}$ was supported. Observing the results of the survey from the aspect of the position of the respondents, it can be concluded that the largest percentage of respondents (54\%) who are employed in the positions of logistics assistant and warehouse managers agreed with this hypothesis. The return of incorrectly delivered products occurs as a consequence of an error noticed by the user and which occurred before the transport process. Values $\beta=0.438, p<0.05$ prove that the return of incorrectly delivered products has an influence on the increase in costs, which supports hypothesis H3d. By crossing the primary business activity of the company in which the respondents work and the H3d hypothesis, it was concluded that the employees in international logistics and freight forwarding mostly agreed with the set hypothesis. Based on the values from Table $4(\beta=0.663, p<0.001)$, it can be concluded that savings can be achieved by efficient quality management of the transport process, which supports hypothesis H3e. Employees in the positions of logistics assistant and dispatcher mostly agreed with this hypothesis. In order to efficiently manage the transport process, logistics companies can apply modern technologies, such as Transportation Management System (TMS) and Intelligent Transportation Systems (ITS). The application of TMS enables the location and tracking of vehicles in real-time, which can reduce the risks associated with longer transport times, poor routing and delivery to the wrong address. By monitoring real-time data using ITS, enables better decision-making and increases flexibility and efficiency. 


\section{Conclusion}

In order for logistics companies to be able to manage their costs, it is necessary to define, measure and control the values of KPIs. KPIs are an excellent basis for assessing the efficiency of the implementation of certain processes, given that based on the value of KPI can be concluded whether the process is efficient. In this paper, a literature review is performed to establish the most commonly used KPIs in subsystems and processes or ordering, warehousing and transport. The review determined that in the ordering subsystem, KPIs that are most often monitored are: total order cycle time, internal order cycle time, perfect order percentage, fill rate, etc. The following KPIs are most often used and monitored in the warehousing subsystem: the cost of reception per pallet, the number of disposed pallets, the cost of storage space per product, the use of storage locations, etc. Finally, in the transport subsystem, the following KPIs are most often used and monitored: delivery reliability, number of on-time deliveries, shipping costs, the efficiency of the distribution process, etc.

Based on the results of the conducted research and hypothesis testing, it was concluded that order flexibility, order processing time and ordering errors have an influence on increasing costs when observing the ordering subsystem. In the warehousing subsystem, re-picking due to error and picking errors influence cost increase, while picking control and the introduction of new picking technologies have an influence on cost reduction. On the other hand, the strategy of vehicle routing and control of loaded goods have a positive effect on reducing costs in the transport subsystem, while the return of incorrectly delivered products and damage during transport have an influence on increasing costs. Effective quality management has an influence on reducing the costs of ordering, warehousing and transport.

This research is the basis for research that would be conducted on a larger sample, but also for research that would include examining the impact of the quality of other subsystems and logistics processes on costs. Also, the results of the conducted research represent a good basis for people from practice. This research was aimed at examining how KPIs, and those related to the quality of logistics processes and subsystems, affect logistics costs. The general conclusion is that the low quality of the process affects the increase in logistics costs. However, the general opinion is that quality costs, so it would be interesting to examine how investing in a high level of quality affects logistics costs. This issue stands out as the direction of future work.

\section{Acknowledgements}

This paper was supported by the Ministry of Education, Science and Technological Development of the Republic of Serbia, through the project TR 36006.

\section{References}

Andrejić, M.; Pajić, V.; Kilibarda, M. 2020. Stress and communication as quality indicators of a working environment in logistics companies: A case study in the logistics sector in Serbia, International Journal for Traffic and Transport Engineering (IJTTE) 10(3): 309-322.

Apsalons, R.; Gromov, G. 2017. Methodology of evaluation of the impact of picking area location on the total costs of warehouse, Transport and Telecommunication 18(4): 332-344. 
Conveyco. 2016. Top order fulfillment: Key Performance Indicators. Available from Internet: <cdn2.hubspot. net/hubfs/2623156/Content/top-order-fulfillmentkpis-conveyco.pdf $>$.

DHL. 2015. Vision picking: Driving innovation for modern supply chains. Available from Internet: <www. dhl.com/content/dam/downloads/g0/logistics/case studies/sc_vision-picking_flyer_en.pdf $>$.

DHL. 2019. DHL Supply chain deoploys latest version of smart glasses worldwide. Available from Internet: <www.dhl.com/global-en/home/press/ press-archive/2019/dhl-supply-chain-deploys-latestversion-of-smart-glasses-worldwide.html>.

Driscoll, M. 2016. Cutting the costs of sales order processing. Available from Internet: <cloud.esker.com >.

Dukic, G.; Oluic, C. 2007. Order-picking methods: improving order-picking efficiency, International Journal of Logistics Systems and Management 3(4): 451-460.

Frazelle, E.H. 2002. World-Class Warehousing and Material Handling. McGraw-Hill Book Company. 56 p.

Germann, R. 2017. How Damaged product impacts Your Profitability, White Paper. 3 p. Available from Internet: <www.rapidpackaging.com/wp-content/ uploads/2017/05/How-Damaged-Product-ImpactsYour-Profitability-Rapid-Packaging.pdf $>$.

Gozacan, N.; Lafci, C. 2020. Evaluation of Key Performance Indicators of Logistics Firms, Logistics \& Sustainable Transport 11(1): 24-32.

Hair, J.; Blac, W.; Babin, B.; Anderson, R.; Tatham, R. 2006. Multivariate Data Analysis. Upper Saddle River, NJ: Pearson Prentice Hall. 31 p.
Helmy, K.A.; ElMokadem, M.Y.; el Bary, A.A.; ElSayeh, M. 2018. The Impact of Logistics Performance on Competitive Advantage: The Case of Freight Transportation in Egypt, Journal of WEI Business and Economics 7(1): 33-47.

Ishfaq, R.; Narayanan, A. 2018. Incorporating OrderFulfillment Flexibility in Automotive Supply Chain through Vehicle Trades, Decision Sciences 50(1): 84-117.

Jakara, M.; Pašagić Škrinjar, J.; Brnjac, N. 2019. Vehicle routing problem - case study on logistics company in Croatia, International Journal for Traffic and Transport Engineering (IJTTE) 9(4): 456-470.

Kryvoruchko, O.; Shynkarenko, V.; Popova, N. 2018. Quality Management of Transport Services: Concept, System Approach, Models of Implementation, International Journal of Engineering \& Technology 7(4.3): 472-476.

Kusrini, E.; Novendri, F.; Helia, V.N. 2018. Determining key performance indicators for warehouse performance measurement - a case study in construction materials warehouse, MATEC Web of Conferences 154(5-6): 1-4.

Li, Z.; Choi, S. 2017. Impacts of Order Cycle Time on the Bullwhip Effect: A Numerical Study, Journal of Management Policies and Practices 5(2): 5-16.

Mensak, C. 2019. E-commerce returns management: the impact of order errors and returns on your customers. Available from Internet: <www.sana-commerce.com/ blog/e-commerce-returns-management-the-impact-oforder-errors-and-returns-on-your-customers $>$.

Mostert, M.; Limbourg, S. 2016. External Costs as Competitiveness Factors for Freight Transport - A State of the Art, Transport Reviews 36(6): 1-21. 
Mungwattana, A.; Soonpracha, K.; Janssens, G.K. 2019. A real-world case study of a vehicle routing problem under uncertain demand, International Journal for Traffic and Transport Engineering (IJTTE) 9(1): 101-117.

Musau, E.G.; Namusonge, G.; Makokha, E.N.; Ngeno, J. 2017. The Effect of Transport Management on Organizational Performance Among Textile Manufacturing Firms in Kenya, International Journal of Academic Research in Business and Social Sciences 7(11): 1015-1031.

Ponboon, S.; Qureshi, A.G.; Taniguchi, E. 2015. Evalutation of cost structure and impact of parameters in location-routing problem with time windows, Transportation Research Procedia 12: 213-226.

Šimkova, I.; Konecny, V.; Liščak, Š.; Stopka, O. 2015. Measuring the quality impacts on the performance in transport company, Transport Problems 10(3): 113-124.

Susanto, T.; Djamaris, A.RA.; Azkia, N. 2016. Process Analysis on Order Processing Function to Reduce Order Processing Time: Indonesian Context, International Journal of Research in Management \& Technology 6(3): 1-14.
Swanson, D. 2016. Transportation price benchmarking: implications for firm performance, Benchmarking: An International Journal 23(4): 1015-1026.

Uthayakumar, R.; Rameswari, M. 2012. An integrated inventory model for a single vendor and single buyer with order-processing cost reduction and process mean, International Journal of Production Research 50(11): 29102924.

Woo, Y.Y.; Hsu, S.L.; Wu, S. 2000. Order processing cost reduction in a joint vendor-buyer inventory system via the application of information technology, The Engineering Economist: A Journal Devoted to the Problems of Capital Investment 45(4): 350-365.

Zimon, D. 2015. The impact of the quality management system for the improvement of warehousing processes. In Proceedings of the 9th International Quality Conference, 43-47. 